\title{
Modelo de Desenvolvimento Participativo de Jogos Digitais Educacionais no Contexto Escolar
}

\section{Dyego Carlos Sales de Morais ${ }^{1}$, Taciana Pontual da Rocha Falcão ${ }^{2}$, Fernando da Fonseca de Souza ${ }^{1}$}

\author{
${ }^{1}$ Centro de Informática - Universidade Federal de Pernambuco - Recife, PE
}

${ }^{2}$ Departamento de Estatística e Informática - Universidade Federal Rural de Pernambuco Recife, PE

moraisdcs@gmail.com, taciana.pontual@ufrpe.br, fdfdecin.ufpe.br

\begin{abstract}
The current generation of young learners demands innovative educational approaches that meet their characteristics and needs. Recent initiatives go beyond the use of games and propose that students can construct games themselves, developing design and programming abilities, and learning curricular contents in more engaging ways. However, integrating digital games to educational settings involves several aspects related to the structure of educational systems and methods of teaching. This research analyzes two school-based processes of game development and identifies aspects that promote student engagement. Results form a model for game development in the educational context.
\end{abstract}

Resumo. Os jovens aprendizes atuais exigem abordagens educacionais inovadoras que atendam às suas características de aprendizagem. As iniciativas recentes vão além do uso de jogos e propõem que os alunos possam construí-los, desenvolver habilidades de design e programação e aprender conteúdos curriculares de maneiras mais atraentes. No entanto, integrar jogos digitais à contextos educacionais envolve vários aspectos relacionados à estrutura dos sistemas educacionais e métodos de ensino. Esta pesquisa analisa dois processos escolares de desenvolvimento de jogos e identifica aspectos que promovem o engajamento dos alunos. Os resultados compõem um um modelo de desenvolvimento de jogos no contexto educacional.

\section{Introdução}

O uso de tecnologias da informação e comunicação nos espaços escolares pode produzir benefícios no processo de construção do conhecimento, uma vez que pessoas consideradas nativas digitais, que tiveram acesso à tecnologia na infância, constroem conhecimento diferentemente dos imigrantes digitais, que não tiveram este acesso [Mattar 2010; Prensky 2001]. Dessa forma, é importante entender as necessidades dos nativos digitais e a estrutura educacional que precisa ser criada de modo a possibilitar uma inserção adequada de tecnologias no contexto escolar.

Uma das idéias recentes para se reconectar com os educandos vem do interesse deles nos jogos digitais. O uso de jogos em processos educacionais obteve resultados positivos, principalmente relacionados ao aumento de engajamento [Wyeth et al. 2013]. No entanto, a introdução de jogos na educação não garante engajamento se for feita como uma ação isolada. Fredricks et al. (2004) destacam que o envolvimento dos educandos é muito reativo às mudanças no contexto - neste caso, os arranjos sociais da escola [Meira e Pinheiro 2012]. Mais do que apenas jogar um jogo, os espaços democráticos que permitem autonomia [Kanthan 2011; Parsons and Taylor 2011], encorajando a colaboração [Kanthan 2011] e a 
participação ativa [Parsons and Taylor 2011], são fundamentais para o engajamento dos educandos. Nesse sentido, emergem algumas iniciativas que propõem não só o uso de jogos na educação, mas a construção destes pelos educandos. Estas iniciativas são uma atualização às idéias originais do construcionismo [Papert e Harel 1991], com a ampla gama de possibilidades trazidas pelas tecnologias atuais, como o acesso facilitado à programação através de ambientes visuais.

A presente pesquisa analisou dois processos de desenvolvimento de jogos digitais por estudantes, ambos baseados em contextos escolares, com o objetivo de investigar quais aspectos dos processos e do ambiente escolar promovem o engajamento dos educandos. Os resultados serviram de evidência e insumos importantes para modelar um processo de desenvolvimento de jogos digitais nas escolas, com suas ferramentas e seus artefatos de mediação, além de ações docentes e gerenciais, contribuindo para propor arranjos inovadores para projetos similares aos investigados. Este artigo apresenta, a seguir, as configurações em que a pesquisa ocorreu, explicando a metodologia de coleta e análise de dados. Em seguida, apresentamos os aspectos encontrados para promover o engajamento em configurações dessa natureza, seguido pelo modelo construído a partir desses resultados. Concluímos indicando como isso se desenvolverá em trabalhos futuros.

\section{Contextos, Materiais e Métodos}

Esta pesquisa foi realizada em duas configurações com projetos onde educandos do ensino médio desenvolvem jogos digitais. O primeiro cenário é uma escola pública de ensino médio integrada com um curso técnico de desenvolvimento de jogos digitais. Os educandos devem escolher se gostariam de ter o papel de designer ou programador na seleção de entrada na escola. Os educadores definem os temas e, no primeiro ano, o briefing dos jogos. Os jogos são desenvolvidos durante o horário das aulas, com o apoio dos educadores, em grupos formados de acordo com as preferências dos educandos. Os educandos são encorajados a realizar pesquisas básicas centradas nos usuários quando os jogos envolvem populações específicas (por exemplo, um projeto sobre diabetes). Eles também são incentivados a participar de competições de desenvolvimento de jogos, como Global Game Jam e SBGames.

O segundo cenário é uma escola de ensino médio público, onde o DEMULTS (projeto de pesquisa transdisciplinar que investiga as relações entre aprendizagem e tecnologia dentro de um processo de desenvolvimento de jogos digitais educacionais) ocorre desde 2012. Com o objetivo de desenvolver jogos que incluem conteúdos curriculares, mas que também são divertidos, o DEMULTS adota o design participativo [Bødker et al. 1995] e a programação do usuário final [Lieberman 2006], à medida que os educandos projetam e desenvolvem jogos cujo público-alvo são eles próprios, seus pares e outros educandos de perfil similar. Os educandos são os líderes no design dos jogos, e os colaboradores da equipe do DEMULTS são como ajudantes. Os educandos são divididos em dois grupos no início do ciclo, de acordo com suas preferências e habilidades: designers e programadores. Eles têm algumas aulas sobre ferramentas de desenvolvimento e os conceitos básicos de jogos digitais (mecânica, personagens, narrativa, etc.), mas a idéia do projeto é que eles aprenderão na prática, com a ajuda dos colaboradores. Cada ciclo DEMULTS visa uma disciplina específica, e cada equipe deve escolher um item curricular dentro desse assunto para integrá-lo na narrativa do jogo.

$\mathrm{Na}$ presente pesquisa, os dados foram coletados através de entrevistas semiestruturadas e observações. No cenário 1 , foram realizadas 10 horas de observação nãoparticipante em aulas de design e programação, e entrevistas foram realizadas com quatro educandos e dois educadores. No cenário 2 , a observação participante foi realizada de agosto de 2015 a julho de 2016 em reuniões de uma hora e meia, uma vez por semana, na escola. 
Quatro estudantes que participaram de ciclos anteriores do projeto foram entrevistados. Enquanto no cenário 1 as observações foram realizadas exclusivamente pelo primeiro autor deste artigo, no cenário 2, toda a equipe do projeto, que incluiu o autor deste trabalho, colaborou com notas de campo da observação participante. Este grupo era formado por dois professores universitários, um estudante de pós-graduação e quatro estudantes de graduação. Dezesseis educandos participaram dos ciclos DEMULTS analisados. A análise qualitativa foi realizada para descobrir quais aspectos engajam os educandos nos processos de desenvolvimento de jogos digitais em contextos escolares. A análise do conteúdo de entrevistas transcritas e notas de campo foi realizada considerando os três indicadores de engajamento selecionados da literatura: autonomia, colaboração e interesse na participação.

\section{Aspectos que promovem engajamento}

A partir de imersão do pesquisador em contextos escolares com práticas pedagógicas de desenvolvimento de jogos digitais por educandos de ensino médio, observaram-se as etapas dos processos, os artefatos utilizados e os aspectos relacionados ao engajamento dos educandos. Sendo os resultados mais relevantes advindos de aspectos promotores de engajamento, apresentados a seguir.

\subsection{Autonomia}

Trabalhar de forma autônoma através de um arranjo social democrático foi considerada uma condição necessária para os processos de desenvolvimento de jogos nas escolas, considerando as características de aprendizagem dos nativos digitais. Os aspectos que promovem a autonomia nos processos analisados foram: escolhas democráticas; abordagem por perguntas e desafios; ambiente de programação adequado; e prazos bem definidos.

Em ambos os cenários, o engajamento foi maior quando os temas, a mecânica e a narrativa dos jogos foram definidos pelos educandos. No DEMULTS, os educandos escolhem o tópico específico dentro de um assunto escolar, através de discussão seguida de votação. Colocar os educandos em locais de decisão cria um ambiente democrático que aproxima o modelo escolar do sócio-interacionismo de Vygotsky (1989), segundo o qual a escola é um lugar cultural para o desenvolvimento do sujeito.

Outra maneira de promover o sócio-interacionismo foi identificada na análise da interação entre educadores e educandos. Quando o educador era perguntado sobre algo, observou-se que incentivar educandos com perguntas, evitando respostas e ordens diretas, foi um bom método para aumentar a autonomia dos educandos. Um exemplo dos dados que se relaciona especificamente com o design gráfico foi observado quando um educador demonstrou a alguns educandos, usando o software, como desenhar facilmente uma tartaruga, para então apagar o que acabara de fazer e desafiar os educandos a fazê-lo. Outra abordagem bem-sucedida identificada foi pedir aos educandos que explicassem como solucionaram um problema pelo qual anteriormente haviam pedido ajuda e, a partir daí, pedir que eles fizessem adaptações à sua solução, se aplicável. Isso aumenta a independência dos educandos, fazendo-os pensar em suas próprias soluções, empregando suas habilidades. Muitas vezes, incitando e não respondendo diretamente, é suficiente (e mais eficiente para aprender) em um processo de solução de problemas.

Um ambiente de programação com feedback imediato, boa usabilidade e permissão de modificação de software em diferentes níveis pelo usuário final [Mørch 1997] é crucial para dar aos educandos a possibilidade de desenvolver suas habilidades de programação de forma autônoma. A extensão do software é um indicador particularmente importante da autonomia 
do educando, não só no processo de desenvolvimento do jogo, mas também na capacidade de desenvolver código próprio, abrindo o caminho para futuros projetos de programação.

Do ponto de vista muito mais prático, mas não menos importantes, os prazos bem definidos foram bastante impactantes sobre a produtividade autônoma dos estudantes. Quando confrontados com uma data fixa para completar uma determinada fase do processo, os educandos se comprometeram a estabelecer um escopo de jogo viável considerando suas habilidades técnicas. Por exemplo, ao discutir os prazos, um educando sugeriu usar apenas batatas como personagens do jogo, porque já haviam sido desenhadas pelos designers, em vez de buscar a idéia atual de ter vários mini-jogos com personagens diferentes. Isso os ajudou a focar e encontrar soluções viáveis, o que é uma habilidade profissional importante.

\subsection{Colaboração}

Mais do que uma necessidade de alcançar metas, a colaboração em ambientes educacionais permite o aprendizado mútuo através do intercâmbio de conhecimento, onde uma pessoa mais avançada pode ajudar um parceiro em seu desenvolvimento pessoal (como discutido por Vygotsky através do conceito de Zona de Desenvolvimento Proximal [Vygotsky, 1989] ). Os principais aspectos relacionados à colaboração identificados nos processos foram: grupos pequenos; tarefas in loco; prazos bem definidos; colaboração do educador em gestão; e colaboração do educador em domínios conceituais e técnicos.

Como na maioria dos contextos educacionais, mesmo em projetos de pesquisa como o DEMULTS, há um pequeno número relativo de educadores para um número maior de educandos. Observou-se que é muito mais provável que um ambiente de aprendizagem sociointeracionista seja bem-sucedido - ou mesmo viável - se os educadores puderem colaborar com pequenos grupos de educandos.

Os educandos apresentaram grandes dificuldades na realização de tarefas quando fisicamente separados. Como todas as tarefas eram passadas para pequenos grupos, eles deveriam colaborar além do horário das reuniões presenciais, principalmente através de tecnologias de comunicação, durante a semana. No entanto, apesar de alguns canais de comunicação disponíveis (no DEMULTS em particular, o Facebook e o Whatsapp foram os mais populares), a colaboração à distância falhou. No cenário 1 , os educandos preferiram ir à escola em horário extra, incluindo sábados, para trabalhar juntos e com educadores.

Além de promover a autonomia, os prazos bem definidos também contribuíram para aumentar a colaboração. As notas de campo relataram que, embora os educandos se queixassem do curto espaço de tempo disponível, a pressão do tempo faz com que sua interação se concentre no trabalho a ser feito coletivamente.

No cenário 2, embora os educandos tentassem se organizar para o desenvolvimento eficiente do jogo, a necessidade de ajuda na gestão das atividades era evidente. Um dos educadores assumiu o papel de gerente, distribuindo atividades de acordo com as habilidades dos educandos e verificando seus progressos. Isso não foi planejado no projeto, o que deu aos educandos bastante autonomia, mas a equipe percebeu uma falta de maturidade para realizar o trabalho sem ajuda organizacional. Provavelmente, com o tempo, os educandos seriam menos dependentes desse suporte para uma colaboração efetiva. Esse pressuposto é respaldado pelo cenário 1 , onde os educandos passam três anos imersos em um processo de desenvolvimento de jogos e têm a oportunidade de desenvolver suas habilidades de autogestão. Eles escolhem representantes para design e programação em cada grupo, para facilitar a colaboração e são capazes de fazê-lo de forma mais autônoma ao passar do tempo.

\subsection{Interesse na Participação}


Ao mostrar interesse em participar de atividades, as pessoas refletem sua preocupação com a qualidade de suas tarefas e produções [Lave e Wenger, 1991]. Nos processos observados, os educandos demonstraram o cuidado para obter jogos de boa qualidade (sendo eles uma passagem de código, uma ilustração ou uma parte da narrativa do jogo). O interesse também foi evidente quando eles apareceram nas reuniões durante as férias escolares ou ficaram nas horas de pós-aula. Os principais aspectos identificados para manter os educandos interessados em participar foram: avaliação periódica, prazos bem definidos, senso de propósito, escolhas democráticas e flexibilidade de papéis.

O cenário 1 é um ambiente educacional formal e, portanto, deve respeitar as regras institucionais. Os educandos devem ser classificados para avançar nos anos escolares, e os protótipos dos jogos desenvolvidos são avaliados periodicamente também como forma de dar feedback aos educandos para ajudá-los a melhorar.

Além de avaliações periódicas, percebeu-se mais uma vez, os prazos bem definidos também como propulsor do interesse em participar. No DEMULTS, o número de educandos que participaram das reuniões aumentou à medida que a data final do projeto se aproximava. Os educandos sentiram a necessidade de terminar o jogo no prazo, e tornaram-se altamente participativos e produtivos. Apesar dos efeitos positivos observados nas três categorias de engajamento, é evidente que os prazos devem ser gerenciados cuidadosamente para evitar extrema pressão e estresse.

O interesse dos educandos em participar dependeu também fortemente do propósito que poderiam atribuir à atividade de desenvolvimento de jogos. Por exemplo, a oportunidade de levar o jogo a uma competição, indo além de passar de ano na escola. Consciente desse fator motivacional extra, os educadores no cenário 1 integram os prazos de uma competição estudantil de desenvolvimento de jogos para o calendário escolar. No cenário 2 (DEMULTS), os educandos ficaram muito motivados pelo fato de seus colegas que não estavam no projeto, bem como outros amigos e familiares, poderem jogar um jogo desenvolvido por eles.

Quando os educandos têm permissão para escolher o tema dos jogos, além de possibilitar maior autonomia, eles demonstram maior interesse em participar ativamente. Em ambos os cenários, os educandos podem optar pelo papel de designer gráfico ou programador, de acordo com suas preferências. No entanto, houve casos de educandos que, ao longo do projeto, perderam interesse nas atividades do papel escolhido e começaram a migrar de forma autônoma e/ou assumir outras responsabilidades. Respeitar a autonomia desses educandos e permitir que eles mudassem de papéis foi crucial para manter sua participação. No cenário 2, alguns educandos começaram como programadores, mas perderam o interesse pela atividade. Eles pararam de contribuir e se tornaram desinteressados. Depois de algum tempo, após mudar o perfil, eles realizaram atividades de design por conta própria e trabalharam de forma autônoma e colaborativa. Busca-se com isto a filosofia do design participativo, onde as pessoas têm influência significativa na concepção do produto e na tomada de decisões, enquanto aprendem uns com os outros [Bødker et al . 1995].

\section{Modelo de Desenvolvimento Participativo de Jogos Digitais Educacionais no Contexto Escolar}

\subsection{Processo}

As etapas do processo desta proposta de modelo são as mesmas do projeto DEMULTS: apresentação, seleção, análise de jogos, ideação, workshops, produção e testes. No entanto, conforme descrição a seguir, algumas mudanças na estrutura dessas etapas são sugeridas.

Devido ao tempo, normalmente curto, disponível para o projeto na escola, indica-se 
que a apresentação e a seleção ocorram juntas, como no DEMULTS. A etapa de análise heurística de jogos digitais educacionais ajuda a compor as referências de jogos dos educandos e iniciar sua formação em noções de game design. Deve-se ter jogos preparados para serem propostos, caso seja percebido que os educandos não possuem muitas referências. Essa etapa ocorre logo após a apresentação e seleção, devido à antecipação da etapa de ideação conforme justificada a seguir.

Entende-se as voltas da etapa de produção para ideação como naturais nos contextos investigados. Esses retornos e a alta complexidade das ideias de jogos propostas pelos educandos, mesmo após o contato com a ferramenta na etapa de aulas e workshops, demonstram que a etapa de ideação não precisaria vir após aulas e workshops. Por exemplo, na etapa de ideação, ao fazer o brainstorm, no qual os educandos deveriam fazer artes apenas para comunicar suas idéias rapidamente, observou-se que faziam artes sofisticadas e gastavase bastante tempo. Portanto, esta etapa de ideação tem o objetivo de explorar o caráter criativo dos participantes, não devendo limitá-lo, deixando para a etapa de produção o momento em que os educandos devem gerenciar suas limitações de tempo disponível e habilidades técnicas necessários para desenvolver os jogos que idealizaram.

Nos encontros após o brainstorm inicial na etapa de ideação, indica-se o aprofundamento do briefing do jogo por meio da concepção de storyboards. Se necessário, como em jogos que precisem de entendimento de contextos muito específicos é indicado fazer pesquisas com usuários externos já nesta etapa. Tudo deve ser documentado e armazenado em um repositório on line. A utilização sistemática dos artefatos mediadores do processo e ferramentas de compartilhamento de arquivos deve ser exposta aos educandos na etapa de ideação. Deve ser criado um quadro de tarefas e apresentado o funcionamento aos educandos ao término dessa etapa.

$\mathrm{Na}$ primeira iteração do processo, entre a ideação e produção há a etapa de workshops. Após essa primeira execução os workshops não devem ser executados outras vezes e o processo ocorre na sequência de ideação-produção-testes. Os workshops devem ter o formato de oficinas práticas, minimizando as aulas expositivas. Além disso, deve-se embasar os conteúdos dos encontros dessa etapa nos conceitos de narrativa, mecânica e regras construídos pelos educandos na etapa de ideação. Por exemplo, a mecânica que já foi escolhida pelos educandos na etapa de ideação, deve ser explorada nos workshops de programação e design, construindo um jogo similar ao idealizado, mas não o mesmo.

Nessa etapa, há a divisão de papéis de atuação: designer e programador. O designer é responsável pelas artes e ilustrações de todos os elementos visuais do jogo. O programador é responsável pelo funcionamento da mecânica e importação de elementos visuais no ambiente de programação. Os workshops de game design e introdução a programação têm a participação de todos. Os seguintes (modificação de software e ilustração digital) são separados e seguem a mesma execução do DEMULTS.

A etapa de produção consiste no desenvolvimento do jogo por meio do ambiente de programação e ferramenta de ilustração digital, seguido de integração entre as produções dos designers e programadores. Em seu início, é preciso haver uma votação para escolha de um representante de design para auxiliar na importação dos elementos visuais (cenário, obstáculos e atores) pelos educandos de programação e um representante de programação para auxiliar na exportação dos elementos visuais pelos educandos de design. Além disso, nesta etapa é importante dar a possibilidade de alguns educandos migrarem de design e programação para assumirem o papel de atuação de game designer. Game designers são os responsáveis por guiar a ideação na etapa de produção e validar o que se desenvolveu pelos programadores e designers. Eles possuem normalmente os papéis de aprendizagem de 
inventor e crítico. Importante mencionar que se nenhum educando voluntariamente migrar para o papel de game designer não há intercorrência no processo.

Indica-se que os encontros de produção devem ocorrer da seguinte forma: (i) inicialmente os educandos designers e programadores fazem apresentações das atividades no quadro de tarefas (o que fizeram, o que estão fazendo e o que falta fazer), e no computador na ferramenta de ilustração digital e no ambiente de programação; e (ii) a utilização do tempo do encontro é voltada principalmente para produzir colaborativamente com educandos e educadores.

No início da produção, conforme visto no cenário 1, e também como forma de incentivar o interesse pela ciência, proporcionando uma experiência de iniciação científica no ensino médio, indica-se que se proponha aos educandos participarem de uma competição ou mostra de jogos com o jogo produzido por eles, desde que o jogo seja validado pelos educadores. Almeja-se com isso o engajamento dos educandos ao conceber um sentido mais amplo à prática que estão inseridos. Indica-se que haja uma apresentação de protótipos com prazos a cada duas semanas, sendo o primeiro protótipo com prazo maior, para experenciarem as ferramentas de programação e design.

A etapa de teste inicia-se com a validação dos educadores sobre o protótipo como testável e visa dar embasamento aos educandos designers, programadores e projetistas para tomadas de decisão do projeto. Pode-se testar com usuários externos ao projeto desde ilustrações, para validar entendimento da narrativa, até a jogabilidade. Ao se testar o protótipo com uma versão jogável, mas não necessariamente com toda a narrativa exposta em elementos de interface do jogo, os educandos devem participar dos testes com usuários externos assumindo todas as responsabilidades: moderação, observação e filmagem.

\subsection{Diretrizes para abordagens pedagógicas}

\subsubsection{Promoção de contexto democrático}

A partir dos aspectos identificados na análise, escolhas democráticas e possibilidade de troca de papel durante o projeto, observados como aspectos que levam a autonomia e interesse na participação, pôde-se criar a diretriz promoção de contexto democrático. Tal diretriz fundamenta-se nos conceitos de design participativo [Bødker, Grønbæk, Kyng 1995] e engajamento, que necessitam desse contexto democrático para serem aplicado e fomentado, respectivamente.

Indicam-se as seguintes ações docentes para aplicação dessa diretriz: (i) possibilitar escolha do tema, mecânica, narrativa e todos os elementos do jogo pelos educandos, por meio de diálogos ou votações. Além da promoção do contexto democrático, esta ação também pode proporcionar mais eficazmente a aprendizagem de conteúdos curriculares, já que espera-se que os educandos sintam-se mais interessados por um tema de sua escolha do que imposto; (ii) possibilitar escolha do local dos encontros pelos educandos, se necessário e quando possibilitado pelo contexto escolar; e(iii) possibilitar troca de papéis de atuação entre designers, programadores e game designers.

\subsubsection{Interação de educandos e educadores}

A partir dos aspectos identificados na análise, abordagem pedagógica por perguntas e desafios, grupos pequenos para facilitar a interação entre educandos e educadores e colaborador/educador como gerente até que os educandos ganhem autonomia para se autogerenciarem, observados como aspectos que levam a autonomia e colaboração, pôde-se criar a diretriz de interação entre educandos e educadores. Tal diretriz fundamenta-se no conceito de Zona de Desenvolvimento Proximal advindo de contribuições da psicologia 
sócio-histórica [Vygotsky 1989].

Indica-se as seguintes ações docentes para aplicação dessa diretriz: (i) possibilitar que o educando explore ao máximo suas habilidades para que consiga por si só solucionar problemas; caso não consiga, auxiliá-lo fazendo perguntas, mas não executando nada até que se esgotem as possibilidades do educando chegar às soluções por si só; (ii) auxiliar o educando por meio da indicação de links com tutoriais ou fóruns de resolução de problemas de programação; (iii) auxiliar o educando e depois pedir para ele explicar o que foi feito ou refazer com pequenas alterações, a fim de que o educando construa uma autonomia por meio de independência posterior ao auxílio a partir do entendimento da prática; e (iv) assumir o papel de gerente no início do processo, organizando o grupo com divisão de trabalho, incluindo criação e manutenção de quadro de tarefas, até que os educandos desenvolvam o autogerenciamento das atividades.

Indica-se a seguinte ação gerencial antes da execução do processo para aplicação dessa diretriz: realizar uma formação de capacitação com os educadores em metodologias participativas e nas abordagens pedagógicas baseadas no sociointeracionismo.

\subsubsection{Aspectos práticos de acompanhamento}

A partir dos aspectos identificados na análise prazos bem definidos, execução presencial de tarefas e avaliação periódica do jogo, observados como aspectos que levam a autonomia, colaboração e interesse na participação ativa, pôde-se criar a diretriz de aspectos práticos de acompanhamento. Tal diretriz diz respeito à interação de educadores e educandos, mais especificamente relacionadas ao acompanhamento da produção do jogo.

Indica-se as seguintes ações docentes para aplicação dessa diretriz: (i) promover atividades e propor tarefas com prazos definidos para o mesmo dia; (ii) exigir dos educandos trabalhos que possam ser executados apenas durante os encontros presenciais do projeto, visando a participação de todos os educandos, já que alguns não possuem infra-estrutura que possibilite o trabalho domiciliar; (iii) definir prazos para avaliação periódica dos jogos, a fim de que os educandos definam o escopo do jogo ponderando suas habilidades técnicas para cumprimento dos prazos; e (iv) promover avaliações periódicas do jogo dos educandos, com banca de avaliação externa ao projeto, por exemplo com docentes que pesquisam ou profissionais de empresas que trabalham com jogos digitais, para que mostrem o que conseguiram fazer rodando no ambiente de programação e no software de ilustração digital.

Além das ações docentes, indica-se também a seguinte característica de arranjo social que deve ser promovido pelo projeto para aplicação desta diretriz: proporção de no máximo 4 educandos por colaborador ou educador para se ter mais atenção e mais tempo disponível para suporte a cada educando.

\subsubsection{Escolha do ambiente de programação}

A partir do aspecto identificado na análise ferramenta de programação adequada, observado como aspecto que leva à autonomia, pôde-se criar a diretriz de escolha do ambiente de programação. Tal diretriz fundamenta-se nos níveis de modificação de software pelo usuário final [Mørch 1997], conceito derivado da programação pelo usuário final [Lieberman et al. 2006], visando um desenvolvimento de habilidades técnicas de programação [Papert e Harel 1991]. Esta diretriz indica que o software escolhido para utilização durante a aplicação do modelo deve possuir boa usabilidade, feedback imediato, linguagem de programação visual e possibilidade de experiência dos três níveis de modificação de software pelo usuário final (customização, integração e extensão) [Mørch 1997].

\subsubsection{Experiência da equipe}


A partir do aspecto identificado na análise, colaboradores que dominem conteúdos curriculares e habilidades técnicas, observado como aspecto que leva à colaboração, pôde-se criar a diretriz experiência da equipe. Tal diretriz fundamenta-se no conceito de Zona de Desenvolvimento Proximal advindo de contribuições da psicologia sócio-histórica, mais especificamente no nível de desenvolvimento real que o educador/colaborador precisa ter sobre um corpo de conhecimento que está transformando ou buscando entender colaborativamente com outros sujeitos no nível potencial [Vygotsky 1989]. Indica-se a seguinte ação gerencial antes da execução do processo para aplicação dessa diretriz: realizar seleção de colaboradores com entrevista e possibilidade de inserção por um período probatório no projeto, a fim de garantir expertise mínima na área em que irá atuar no projeto (conteúdos curriculares ou habilidades técnicas).

\subsubsection{Fatores externos}

A partir do aspecto identificado na análise propósitos que vão além do próprio produto e da aprendizagem, observado como aspecto que leva ao interesse na participação ativa, pôde-se criar a diretriz de fatores externos. Tal diretriz é importante para que os educandos possuam um motivo para se preocuparem com a qualidade do jogo que vá além da aprendizagem e da concepção do jogo em si. Acredita-se que isto corrobora para que se interessem pela participação ativa, pois ao buscarem a qualidade do jogo, se engajam e aprendem conteúdos curriculares e desenvolvem habilidades técnicas.

Indica-se a seguinte ação docente para aplicação dessa diretriz: propor a participação em competições e outros eventos de demonstração de jogos, incluindo os educandos que optarem por isso como autores na submissão do jogo, a fim de promover o interesse na participação a partir de propósitos que vão além do contexto do projeto.

\section{Conclusões}

As principais contribuições deste trabalho foram: (i) identificação de etapas e artefatos de processos de desenvolvimento de jogos digitais educacionais no contexto escolar; (ii) identificação de indicadores e aspectos que promovem engajamento nesses processos; e (iii) elaboração de modelo de desenvolvimento participativo de jogos digitais educacionais no contexto escolar com etapas, artefatos, e, principalmente diretrizes para ações docentes e gerenciais.

As limitações e contribuições apontam para os seguintes trabalhos futuros: (i) validação do modelo por meio de execução plena de um ciclo no projeto DEMULTS ou em outro contexto similar; (ii) análise comparativa a partir de aplicações do modelo como proposto neste trabalho e com alterações, por exemplo extinguindo a etapa de workshops e permitindo execução ativa de atividades iniciais por colaboradores na etapa de produção; (iii) estudos longitudinais para investigar os aspectos que levam às mudanças dos papéis do design participativo de cada participante; e (iv) estudos mais aprofundados de construcionismo, pensamento computacional e ensino de computação que explorem outros métodos, como investigação de código, para evidenciar aprendizagem de computação.

\section{Referências}

Bødker, S.; Grønbæk, K. and Kyng, M. (1995). "Cooperative design: techniques and experiences from the Scandinavian scene". In: Readings in Human-Computer Interaction: Toward the Year 2000. Morgan-Kaufmann. 
VI Congresso Brasileiro de Informática na Educação (CBIE 2017)

Anais dos Workshops do VI Congresso Brasileiro de Informática na Educação (WCBIE 2017)

Fredricks, J. A.; Blumenfeld, P. C. and Paris, A. H. (2004). "School engagement: Potential of the concept, state of the evidence". In: Review of educational research, Sage Publications, v. 74, n. 1, p. $59-109$.

Kanthan, G. D/O S. (2011). "Strengthening student engagement in the classroom". Dissertation. National University of Singapore - Faculty of Science.

Lave, J. and Wenger, E. (1991). "Situated learning: legitimate peripheral participation". Cambridge University Press.

Lieberman, H. et al. (2006). "End-user development: An emerging paradigm". In: End user development, Springer. p. $1-8$.

Mattar, J. (2010). "Games em educação: como os nativos digitais aprendem". São Paulo: Pearson Prentice Hall.

Meira, L. and Pinheiro, M. (2012). Inovação na escola. In: XI Brazilian Symposium of Games and Digital Enterteinament. Brasília, Brazil.

Mørch A. (1997). "Three levels of end-user tailoring: Customization, integration, and extension". In: Computers and design in contexto. MIT Press, Cambridge, USA, p. 51 76.

Papert, S. and Harel, I. (1991). "Situating constructionism". Constructionism, v. 36, p. 1 - 11.

Parsons, J. and Taylor, L. (2011). "Improving student engagement". Current issues in education, v. 14, n. 1.

Prensky, M. (2001). "Digital natives, digital immigrants". Part 1. On the horizon, MCB UP Ltd, v. 9, n. 5, p. $1-6$.

Vygotsky, L. S. (1989). "Pensamento e linguagem". Ridendo Castigat Mores.

Wyeth, P.; Johnson, D. and Ziviani, J. (2013). "Activity, motivation and games for young children". In: ACM. Proceedings of The 9th Australasian Conference on Interactive Entertainment: Matters of Life and Death. 